\title{
Forragem hidropônica no ecótono Cerrado Pantanal
}

\author{
Hydroponic forage in the Cerrado Pantanal ecotonon \\ Forraje hidropónico en el Cerrado Pantanal ecotone
}

Recebido: 09/05/2021 | Revisado: 16/05/2021 | Aceito: 18/05/2021 | Publicado: 06/06/2021

Dthenifer Cordeiro Santana

ORCID: https://orcid.org/0000-0001-7611-6040

Universidade Estadual Paulista "Júlio de Mesquita Filho", Brasil

dthenifer.santana@unesp.br

Ana Caroline Mello Arevalo

ORCID: https://orcid.org/0000-0002-1277-1553

Universidade Estadual de Mato Grosso do Sul, Brasil

E-mail: melloarevalo@gmail.com

Pablo Rozo Silva

ORCID: https://orcid.org/0000-0002-1213-3682

Universidade Estadual de Mato Grosso do Sul, Brasil

E-mail: pablo.rozo@ hotmail.com

Marcos Jefferson Kraeski

ORCID: https://orcid.org/0000-0002-1026-8057

Universidade Estadual de Mato Grosso do Sul, Brasil

E-mail: marcoskraeski@gmail.com

Laura Matos Ribera

ORCID: https://orcid.org/0000-0003-1570-7714

Universidade Estadual Paulista "Júlio de Mesquita Filho", Brasil

E-mail: laura.ribera@unesp.br

Francisco Eduardo Torres

ORCID: https://orcid.org/0000-0002-6114-0096

Universidade Estadual de Mato Grosso do Sul, Brasil

E-mail: feduardo10@gmail.com

\begin{abstract}
Resumo
A forragem hidropônica é uma tecnologia de produção de período curto, produção contínua, cultivo em todas as estações do ano, produtividade elevada, baixo consumo de água. Buscando reverter as adversidades climáticas sofrida pelos produtores para alimentar seus animais, objetivo deste trabalho foi avaliar a produtividade e a qualidade da forragem hidropônica no ecótono Cerrado-Pantanal, buscando determinar a espécie e a solução mais adequada para a região. Foram conduzidos dois experimentos na Universidade Estadual de Mato Grosso do Sul, no município de Aquidauana - MS, em casa de vegetação com tela de sombreamento de $50 \%$. O primeiro experimento foi implementado no mês de março e o segundo no mês de setembro, ambos sendo conduzido por 15 dias. O delineamento experimental foi em blocos ao acaso, em parcelas subdivididas. A parcela foi formada pelas soluções (mineral e orgânica) e as subparcelas foram as populações (100\% milho, 100\% milho +8 sementes de mucuna, 100\% milheto, $50 \%$ milho $+50 \%$ milheto, $75 \%$ milho $+25 \%$ milheto e $25 \%$ milho $+75 \%$ milheto) com quatro repetições totalizando 12 tratamentos. As parcelas continham $1 \mathrm{~m}^{2}$ e receberam 4 litros de sua respectiva solução durante 11 dias. A população constituída de $25 \%$ milho e $75 \%$ milheto irrigada com solução mineral apresentou melhor qualidade de forragem quanto a proteína bruta. A população de milho e milho + mucuna obtiveram maior matéria seca independente da solução.
\end{abstract}

Palavras-chave: Fertirrigação; Veranico; Volumoso.

\section{Abstract}

Hydroponic fodder is a short-term production technology, continuous production, cultivation in all seasons, high productivity, low water consumption. Seeking to reverse the climatic adversities suffered by producers to feed their animals, the objective of this work was to evaluate the productivity and the quality of hydroponic forage in the Cerrado-Pantanal ecotone, seeking to determine the species and the most appropriate solution for the region. Two experiments were carried out at the State University of Mato Grosso do Sul, in the municipality of Aquidauana - MS, in a greenhouse with a 50\% shading screen. The first experiment was implemented in March and the second in September, both being conducted for 15 days. The experimental design was in randomized blocks, in subdivided plots. The plot was formed by the solutions (mineral and organic) and the subplots were the populations (100\% corn, $100 \%$ corn +8 mucuna seeds, $100 \%$ millet, $50 \%$ corn $+50 \%$ millet, $75 \%$ corn $+25 \%$ millet and $25 \%$ corn $+75 \%$ millet) with four replications totaling 12 treatments. The plots contained $1 \mathrm{~m} 2$ and received 4 liters of their respective solution for 11 days. The population constituted of $25 \%$ corn and $75 \%$ millet irrigated with mineral solution showed 
better quality of forage in terms of crude protein. The population of maize and maize + mucuna obtained the highest dry matter regardless of the solution.

Keywords: Fertigation; Summery; Bulky.

\section{Resumen}

El forraje hidropónico es una tecnología de producción a corto plazo, producción continua, cultivo en todas las estaciones, alta productividad, bajo consumo de agua. Buscando revertir las adversidades climáticas que sufren los productores para alimentar a sus animales, el objetivo de este trabajo fue evaluar la productividad y la calidad del forraje hidropónico en el ecotono Cerrado-Pantanal, buscando determinar la especie y la solución más adecuada para la región. . Se llevaron a cabo dos experimentos en la Universidad Estatal de Mato Grosso do Sul, en el municipio de Aquidauana - MS, en un invernadero con una pantalla de sombra al 50\%. El primer experimento se implementó en marzo y el segundo en septiembre, ambos llevados a cabo durante 15 días. El diseño experimental fue en bloques al azar, en parcelas subdivididas. La parcela estuvo formada por las soluciones (mineral y orgánica) y las subparcelas fueron las poblaciones (100\% maíz, $100 \%$ maíz +8 semillas de mucuna, $100 \%$ mijo, $50 \%$ maíz $+50 \%$ mijo, $75 \%$ maíz $+25 \%$ mijo y $25 \%$ maíz $+75 \%$ mijo) con cuatro repeticiones totalizando 12 tratamientos. Las parcelas contenían $1 \mathrm{~m} 2$ y recibieron 4 litros de su respectiva solución durante 11 días. La población compuesta por un $25 \%$ de maíz y un $75 \%$ de mijo regada con solución mineral mostró mejor calidad de forraje en términos de proteína cruda. La población de maíz y maíz + mucuna obtuvo la mayor cantidad de materia seca independientemente de la solución.

Palabras clave: Fertirrigación; Verano; Voluminosos.

\section{Introdução}

Existem diversas espécies que podem ser utilizadas como forrageiras para a alimentação animal. Fontaneli et al. (2012) asseguram que ao escolher uma espécie forrageira devemos considerar sua produtividade e qualidade nutritiva, bem como sua adaptação ao clima, tipo de solo do local e o sistema de cultivo.

A forragem hidropônica se destaca por ser uma tecnologia de produção que tem como principais vantagens ciclo curto, menor risco com adversidades meteorológicas, produção contínua, cultivo em todas as estações do ano, produtividade elevada, baixo consumo de água. Além disso, nesse sistema são ministradas soluções nutritivas diariamente, que fornecem as plantas os nutrientes necessários para um bom desenvolvimento (Píccolo et al., 2013).

Dentre os tipos de substratos utilizados para a forragem hidropônica, a cana de açúcar se destaca por estar presente em grande parte das pequenas e médias propriedades, além de atender as características desejadas. Diversos trabalhos utilizaram a cana de açúcar ou o seu bagaço oriundo de usinas de álcool para a produção de forragem hidropônica (Araujo et al., 2008; Píccolo et al., 2013).

A solução nutritiva pode ser produzida com produtos de origem mineral, que geralmente apresenta alto custo, dificultando a adoção dessa tecnologia por pequenos produtores ou menos capitalizados, e pode também ser produzida com produtos de origem orgânica, possibilitando a redução de custos, utilizando leite, esterco bovino, açúcar e água, todos itens de fácil acesso e baixo custo. Vale ressaltar que a solução deve ser preparada em função da cultura utilizada, em razão das necessidades nutricionais de cada espécie. De modo que a concentração dos nutrientes, o pH e a pressão osmótica variem entre as soluções, seja ela orgânica ou mineral. A solução nutritiva utilizada deve fornecer o mínimo de nutrientes e a quantidade adequada para cada espécie (Píccolo et al., 2013).

A definição da espécie a ser utilizada na forragem hidropônica deve considerar a quantidade, a qualidade do material produzido e a adaptabilidade, ao sistema de produção. A cultura do milho, é utilizada na alimentação animal na forma de ração e de silagem (Silva et al., 2018; Heberle et al., 2019). Os estudos de forragem hidropônica realizados por Cunha e Silva (2017) e nos de Santana et al. (2020) evidenciaram que a cultura apresenta bons resultados com essa forma de cultivo.

A cultura do milheto também é utilizada na produção de forragem hidropônica. Müller et al. (2006) relataram que esta espécie pode proporcionar boa qualidade nutricional e quantidade relativamente alta. Santana et al. (2020) obtiveram valores de fibra em detergente neutro e ácido na cultura do milheto semelhantes aos obtidos na cultura do milho. Os autores destacam 
que estes fatores formam um parâmetro essencial na determinação da qualidade da forragem, visto que inclui a digestibilidade do animal a fibras.

Algumas espécies de leguminosas podem ser utilizadas, de acordo com as condições edafoclimáticas, em consórcio com gramíneas, apresentando resultados promissores, podendo proporcionar melhoria na qualidade das forragens e maiores ganhos de peso animal (Stivari et al., 2011). A mucuna preta, na alimentação de bovinos, é rica em proteína.

Ainda são escassos os trabalhos que determinem a solução nutritiva e a espécie forrageira para o sistema de forragem hidropônico. Com isso o objetivo deste trabalho foi avaliar a produtividade e a qualidade da forragem hidropônica no ecótono Cerrado-Pantanal, buscando determinar a espécie e a solução mais adequada para a região

\section{Metodologia}

Foram conduzidos dois experimentos na Universidade Estadual de Mato Grosso do Sul, no município de Aquidauana - MS, em casa de vegetação com tela de sombreamento de 50\%. O primeiro experimento foi implementado no mês de março e o segundo no mês de setembro, ambos sendo conduzido por 15 dias. O município se encontra na região de ecótono Cerrado-

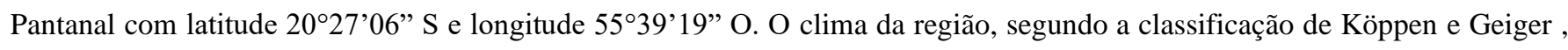
enquadra-se ao tipo Aw (tropical de savana). A temperatura média é de $24,2{ }^{\circ} \mathrm{C}$ e a pluviosidade média anual é de 1.450 milímetros (CLIMA DATA).

O delineamento experimental foi em blocos casualizados, em parcelas subdivididas e teve caráter quantitativo. A parcela foi formada pelas soluções (mineral e orgânica) e as subparcelas foram as populações (100\% milho, $100 \%$ milho +8 sementes de mucuna, $100 \%$ milheto, $50 \%$ milho $+50 \%$ milheto, $75 \%$ milho $+25 \%$ milheto e $25 \%$ milho $+75 \%$ milheto) com quatro repetições totalizando 12 tratamentos (Tabela 1). As parcelas continham $1 \mathrm{~m}^{2}$ e receberam 4 litros de sua respectiva solução durante 11 dias. Nos dois primeiros dias e os dois últimos foram irrigados com água na mesma quantidade, os procedimentos realizados quanto a instalação e condução do experimento foram baseados na metodologia de Piccolo et al. (2013).

Tabela 1. Tratamentos utilizados no experimento.

\begin{tabular}{ccc}
\hline Tratamento & Parcela & Subparcela \\
\hline T1 & Mineral & $100 \%$ milho \\
T2 & Orgânica & $100 \%$ milho \\
T3 & Mineral & $100 \%$ milheto \\
T4 & Orgânica & $100 \%$ milheto \\
T5 & Mineral & $100 \%$ milho + Mucuna \\
T6 & Orgânica & $100 \%$ milho + Mucuna \\
T7 & Mineral & $50 \%$ milho $+50 \%$ milheto \\
T8 & Orgânica & $50 \%$ milho $+50 \%$ milheto \\
T9 & Mineral & $75 \%$ milho $+25 \%$ milheto \\
T10 & Orgânica & $75 \%$ milho $+25 \%$ milheto \\
T11 & Mineral & $25 \%$ milho $+75 \%$ milheto \\
T12 & Orgânica & $25 \%$ milho $+75 \%$ milheto \\
\hline
\end{tabular}

Fonte: Autores.

Impedindo o contato das plantas com o solo, uma lona plástica de dupla face de 150 micras foi utilizada sob o solo, com o lado preto para baixo e o lado branco para cima. Sobre a lona foi depositado o substrato de cana-de-açúcar picada, aproximadamente 4 centímetros. Cada parcela compunha $1 \mathrm{~m}^{2}$ totalizando 48 parcelas. 
As sementes estavam livres de tratamentos, e para auxiliar na germinação ficaram imersas em água por 24 horas. As sementes foram distribuídas uniformemente sobre as parcelas, onde a parcela de 100\% milheto e 100\% milho receberam $2 \mathrm{~kg}$ de sementes; $100 \%$ milho com mucuna: $2 \mathrm{~kg}$ de sementes de milho e oito sementes de mucuna; $75 \%$ milho e $25 \%$ milheto: 1,5 $\mathrm{kg}$ de milho e $0,5 \mathrm{~kg}$ de milheto respectivamente; $50 \%$ milho e $50 \%$ milheto: foram $1 \mathrm{~kg}$ de milho e $1 \mathrm{~kg}$ milheto; $25 \%$ milho e $75 \%$ milheto: $0,5 \mathrm{~kg}$ milho e 1,5 milheto.

A solução mineral foi produzida no laboratório de química da unidade seguindo uma solução padrão para milho contendo nitrato de cálcio (410 g), nitrato de potássio (360 g), sulfato de magnésio (150 g), monoamônio fosfato (90 g) e Fe-EDTA (35 g), todos diluídos em 1.000 litros de água. A solução de micronutrientes exceto o Fe-EDTA foi diluída em cinco litros, na qual foi utilizado: $22 \mathrm{~g}$ de bórax, 4,5 $\mathrm{g}$ de sulfato de manganês, 9,5 $\mathrm{g}$ de sulfato de zinco, 4,0 $\mathrm{g}$ de sulfato de cobre e 1,5 g de molibdato de sódio (Neves, 2009).

O preparo da solução orgânica foi realizado no setor de olericultura da unidade, utilizando dejetos verdes de bovinos provenientes do setor de Bovinocultura de Leite. Para o seu preparo utilizou-se 70 quilos de esterco (fresco) de vacas em lactação, 120 litros de água, $5 \mathrm{~kg}$ de açúcar e $5 \mathrm{~L}$ de leite para acelerar o processo fermentativo. Após 20 dias, a solução foi diluída na proporção de $21 \mathrm{~mL}$ da solução nutritiva orgânica para 20 litros de água. A caracterização química da solução orgânica se encontra na Tabela 2.

Tabela 2. Caracterização química da solução orgânica.

\begin{tabular}{cccccccccc}
\hline $\mathrm{N}$ & $\mathrm{P}$ & $\mathrm{K}$ & $\mathrm{Ca}$ & $\mathrm{Mg}$ & $\mathrm{S}$ & $\mathrm{Cu}$ & $\mathrm{Fe}$ & $\mathrm{Zn}$ & $\mathrm{Mn}$ \\
$\mathbf{-} 697,9$ & 20,55 & 322,64 & 477,62 & 98,23 & 19,67 & 0,12 & 38,38 & 0,12 & 4,12 \\
\hline
\end{tabular}

*N=nitrogênio; $\mathrm{P}=$ fósforo; $\mathrm{K}=$ potássio; $\mathrm{Ca}=$ cálcio; $\mathrm{Mg}=$ magnésio; $\mathrm{S}=$ enxofre; $\mathrm{Cu}=$ cobre; $\mathrm{Fe}=$ ferro; $\mathrm{Zn}=$ zinco; $\mathrm{Mn}=$ manganês. Fonte: Autores.

Nos dois primeiros dias de experimento, as parcelas receberam apenas água, a partir do terceiro até o décimo terceiro receberam as soluções nutritivas e nos dois últimos dias, irrigados apenas com água novamente, totalizando 15 dias de experimento. As parcelas foram divididas para que cada população recebesse solução orgânica e mineral separadamente, de forma que não haja influência de umas sobre as outras.

Aos 15 dias foi realizada a coleta da parte aérea da forragem, utilizando todo o material verde da parcela o separandoo do substrato com o auxílio de uma tesoura. As amostras foram pesadas e levadas para a estufa de circulação forçada de ar a $65{ }^{\circ} \mathrm{C}$ até massa constante. Para avaliação do substrato, foi retirada amostra de $0,25 \mathrm{~m}^{2}$ da área útil da parcela, também sendo pesada e colocada na estufa de circulação forçada de ar a $65^{\circ} \mathrm{C}$ até massa constante. Após secas, as amostras foram novamente pesadas e moídas em moinho do tipo Willey, colocadas em saquinhos identificados para ser utilizados nas análises laboratoriais. O procedimento em laboratório foi seguido de acordo com a metodologia por Kjeldahl.

Os dados foram submetidos a análise de variância e as médias comparadas pelo teste de Tukey a 5\% de probabilidade, analisadas no software R (R Development Core Team, 2014). A análise multivariada de variáveis canônicas foi realizada no software Rbio (Bhering, L. L. 2017).

\section{Resultados e Discussão}

$\mathrm{Na}$ análise de variância pelo teste de Tukey (Tabela 3) são apresentados os valores encontrados para as variáveis massa seca e proteína bruta de forragem hidropônica com 15 dias de desenvolvimento. Houve diferença significativa para solução, quanto à variável proteína bruta (nível de $5 \%$ de significância) e diferença significativa para população, quanto às 
variáveis proteína bruta e massa seca (nível de $0,1 \%$ de significância). Houve interação significativa para população dentro da solução quanto a variável proteína bruta (nível de $1 \%$ de significância).

Tabela 3. P-valor do teste de Tukey para Massa seca (MS) e proteína bruta (PB) da parte aérea para seis populações de forragens cultivadas no ecótono Cerrado-Pantanal.

\begin{tabular}{lcc}
\hline FV & PB & MS \\
\hline BLOCO & $\%$ & \\
SOL. & $0.23^{\mathrm{NS}}$ & $0.81^{\mathrm{NS}}$ \\
POP. & $0.04^{*}$ & $0.84^{\mathrm{NS}}$ \\
POP*SOL & $0.00^{* * *}$ & $0.00^{* * *}$ \\
CV 1 & $0.00^{* *}$ & $0.88^{\mathrm{NS}}$ \\
CV 2 & 6.55 & 22.46 \\
\hline
\end{tabular}

$\mathrm{POP}=$ população; $\mathrm{SOL}=$ solução; $\mathrm{CV} 1=$ coeficiente de variação da parcela; $\mathrm{CV} 2=$ coeficiente de variação da subparcela; significativo ao teste de Tukey a '***’ 0.001 '**’ 0.01 '*’ $0.05 \%$ de probabilidade. NS não significativo Fonte: Autores.

Os valores das variáveis encontrados por Carvalho et al. (2016) foram superiores a este estudo quanto a matéria seca e proteína bruta de milho forrageiro, respectivamente, $31,25 \%$ e 7,15\%. A diferença entre valores na pesquisa anterior, pode ser justificada pela época de cultivo da forrageira (dezembro a março), as condições experimentais (a área foi utilizada anteriormente para o cultivo de braquiária brizantha cv. Marandu) e a data da colheita diferentes. Portanto, o estádio no qual as forragens são colhidas e ensiladas demudam a qualidade e o valor nutritivo destas no que se refere a proteína bruta e matéria seca (Vilela et al., 2008).

No desdobramento da interação significativa das populações dentro da solução quanto à variável proteína bruta (Tabela 4), é possível inferir que as forragens, quanto a solução mineral e orgânica, não houve diferença estatística. Exceto para a população com $25 \%$ milho, a qual a solução mineral proporcionou incremento de $12,34 \%$ de PB, valor este superior quando comparada as demais populações $(6,58 \% ; 6,16 \% ; 6,26 \% ; 6,46 \%$ e $6,84 \%)$ e quando comparada a solução orgânica $(6,29 \%)$. Corroborando desta forma, melhor desempenho da variável analisada na região de estudo.

Tabela 4. Desdobramento das variáveis Proteína Bruta (PB) da parte aérea forragem hidropônica sob diferentes soluções e populações cultivadas no ecótono Cerrado-Pantanal.

\begin{tabular}{lcc}
\hline \multirow{2}{*}{ População } & \multicolumn{2}{c}{ PB } \\
\cline { 2 - 3 } & Mineral & Orgânica \\
\hline $100 \%$ Milheto & $6.58 \mathrm{bA}$ & $6.20 \mathrm{aA}$ \\
$100 \%$ Milho & $6.16 \mathrm{bA}$ & $8.31 \mathrm{aA}$ \\
$100 \%$ Milho + Mucuna & $6.26 \mathrm{bA}$ & $5.73 \mathrm{aA}$ \\
$75 \%$ milho & $6.46 \mathrm{bA}$ & $5.60 \mathrm{aA}$ \\
$50 \%$ milho & $6.84 \mathrm{bA}$ & $5.78 \mathrm{aA}$ \\
$25 \%$ milho & $12.34 \mathrm{aA}$ & $6.29 \mathrm{aB}$ \\
\hline
\end{tabular}

* Média de mesma letra maiúscula na linha e minúscula na coluna não diferem entre si pelo teste de Tukey a 5\% de probabilidade. Fonte: Autores.

Para Píccolo et al. (2012) ao estudar forragem hidropônica de milho utilizando-se água residuária de bovinos e colhida após 15 dias, obteve que o resíduo orgânico pode ser utilizado como substituto a solução padrão (mineral) utilizada para milho forrageiro. Colaborando, em partes, com os dados obtidos neste estudo, visto que não houve diferença, em quase todas as soluções e populações. Somente houve diferença no resultado quando se utilizou população $25 \%$ milho, sendo esta, superior a todos os outros. 
Valores de proteína bruta são relevantes para recomendação da forrageira ao animal, nesta pesquisa obteve-se na condição supracitada, valor de PB acima da média (12,34\%) comumente verificada para silagem de milho, em torno, de 8,50\% (Zago, 1997), citado por (Lourenço Júnior et al., 2004). Fraga et al. (2009) ao estudar dois diferentes substratos e sua influência em variedades de milho forrageiro sob soluções minerais associados ao substrato bagaço de cana, obteve valores de PB de 10,50\%, 11,49\% e 11,57\% para cada variedade, valores estes inferiores ao obtido pela melhor média neste estudo.

Na Figura 1 observa-se que as melhores médias foram obtidas na população de milho e de milho + mucuna para variável matéria seca. Zorzan (2006) ao estudar a qualidade da forragem hidropônica envolvendo leguminosas e gramíneas, para a variável massa seca, obteve no centeio produzido no inverno a melhor média $(89,6 \%)$ superando a forragem de cevada e a forragem com culturas consorciadas. Neste estudo, não houve diferença estatística na MS, nas populações de gramínea (milho), nem quando existiu a associação entre a gramínea (milho) e leguminosa (mucuna).

Figura 1. Avaliação da variável matéria seca das populações de forragem hidropônica sob diferentes soluções e populações cultivadas no ecótono Cerrado-Pantanal.

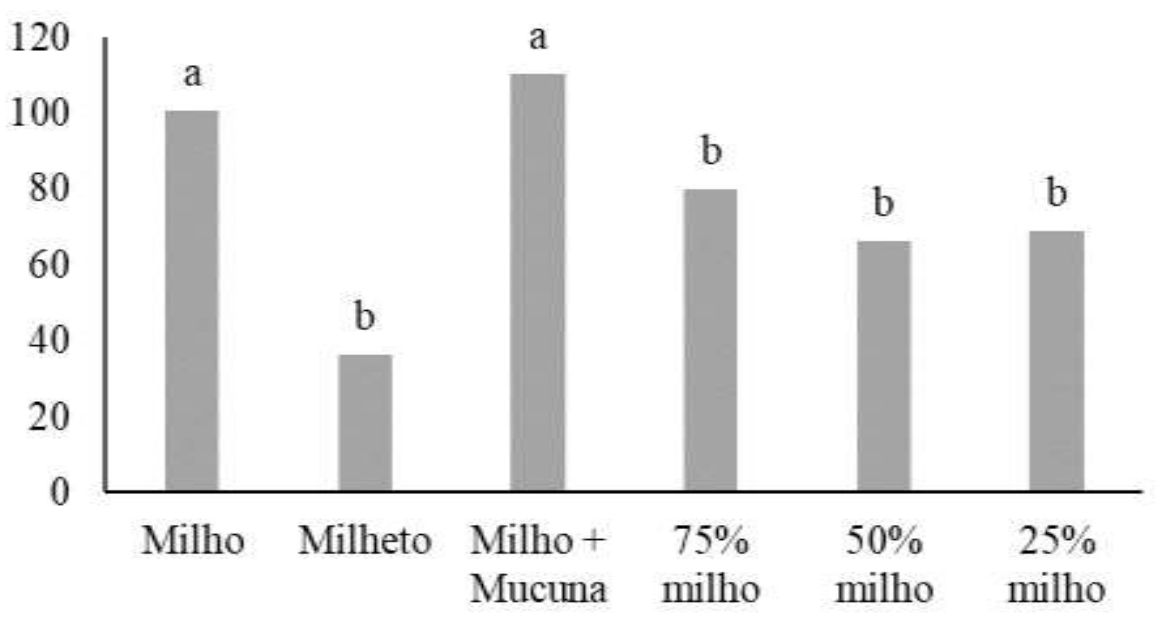

Fonte: Autores.

Píccolo (2012) obteve para a forragem de milho utilizando-se como substrato o capim Napier, o valor máximo de massa seca da parte aérea de $0,051 \mathrm{~kg} \mathrm{~m}^{2}$ quando utilizada uma solução orgânica de água residuária de bovinos, comparada a solução mineral. Rodrigues et al. (2017) em seu estudo utilizando esterco bovino para fertirrigação em forragem hidropônica de milho, com $15 \%$ de biofertilizante e $85 \%$ de água, obteve o maior valor para matéria seca $0,070 \mathrm{~g}$ colhida 20 dias após a semeadura, valores estes inferiores ao produzido pelo milho e pelo milho + mucuna.

Efeitos das soluções na variável matéria seca das populações de forragem hidropônica sob diferentes soluções e populações pode ser observado na Figura 2. 
Figura 2. Efeitos das soluções na variável matéria seca das populações de forragem hidropônica sob diferentes soluções e populações cultivadas no ecótono Cerrado-Pantanal.

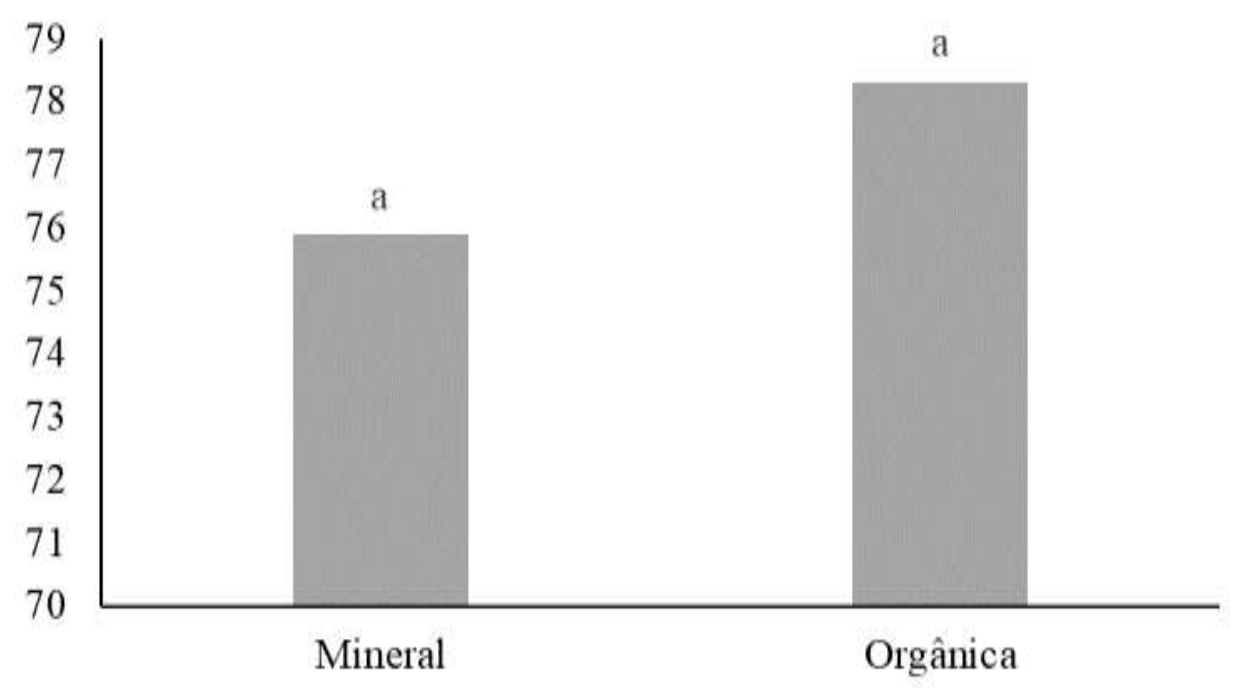

Fonte: Autores.

Pode se observar que para a variável matéria seca de forragem hidropônica quanto a solução orgânica e solução mineral não houve diferença significativa a $5 \%$ de probabilidade.

Para expressar a relação entre as variáveis e as populações foi construído uma análise de variáveis canônicas para cada ciclo. Para a variável PB a população milho e milheto irrigado com solução orgânica alcançaram maiores médias. Para a variável matéria seca as populações milho com mucuna irrigado com solução mineral e a população que continha $25 \%$ milho irrigado com solução orgânica obteve maiores médias. Simonetti et al., (2016) constataram que o uso de biofertilizante nas pastagens apresenta resultados significativos na produtividade e no teor de proteína. 
Figura 3. Análise de variáveis canônicas para o primeiro ciclo de instalação do experimento avaliando as variáveis proteína bruta (PB) e massa seca (MS) para as populações.

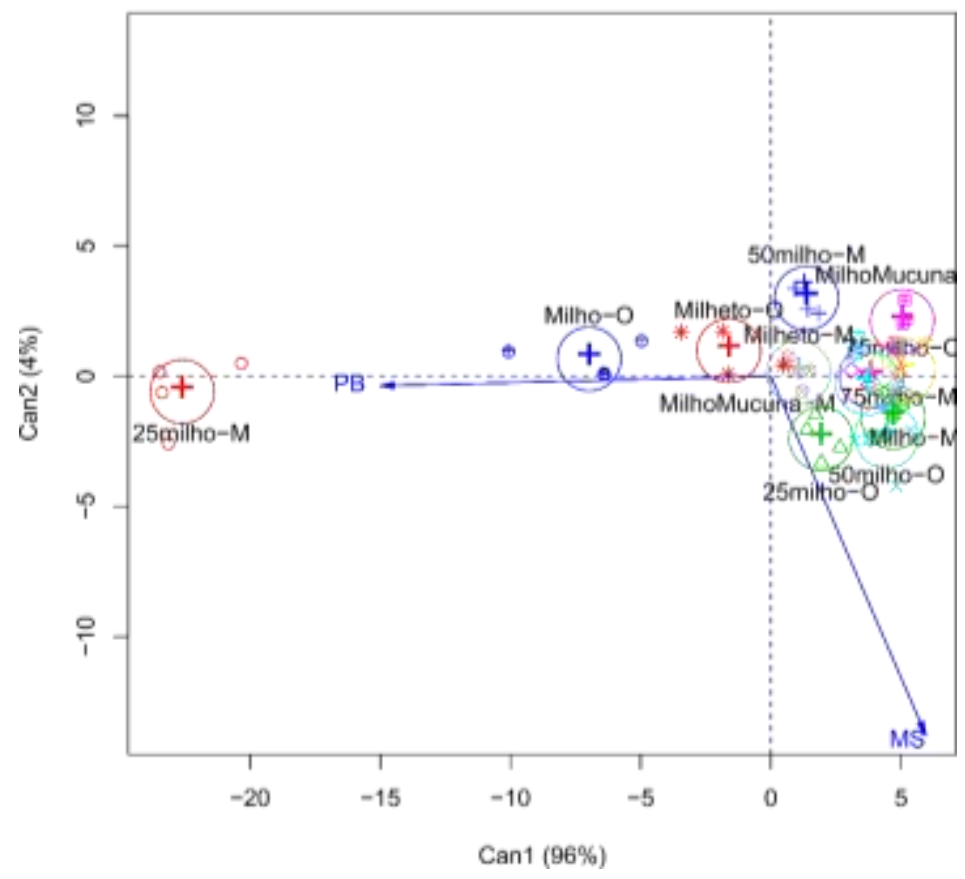

Fonte: Autores.

Para a avaliação no segundo ciclo, PB as populações 75\% milho e 50\% milho irrigadas com solução mineral e 75\% milho irrigado com solução orgânica obtiveram maiores médias para essa variável. Para matéria seca as variáveis milho com mucuna, $75 \%$ milho e a população de milho com mucuna irrigada com solução mineral obtiveram maiores médias. Para ambas as variáveis é notável que a maior população de milho são as que alcançaram maiores médias. Essa é uma característica própria do uso de milho para esse tipo de sistema que possui esse potencial elevado de produção de MS (Neumann et al., 2017). 
Figura 4. Análise de variáveis canônicas para o segundo ciclo de instalação do experimento avaliando as variáveis proteína bruta (PB) e massa seca (MS) para as populações.

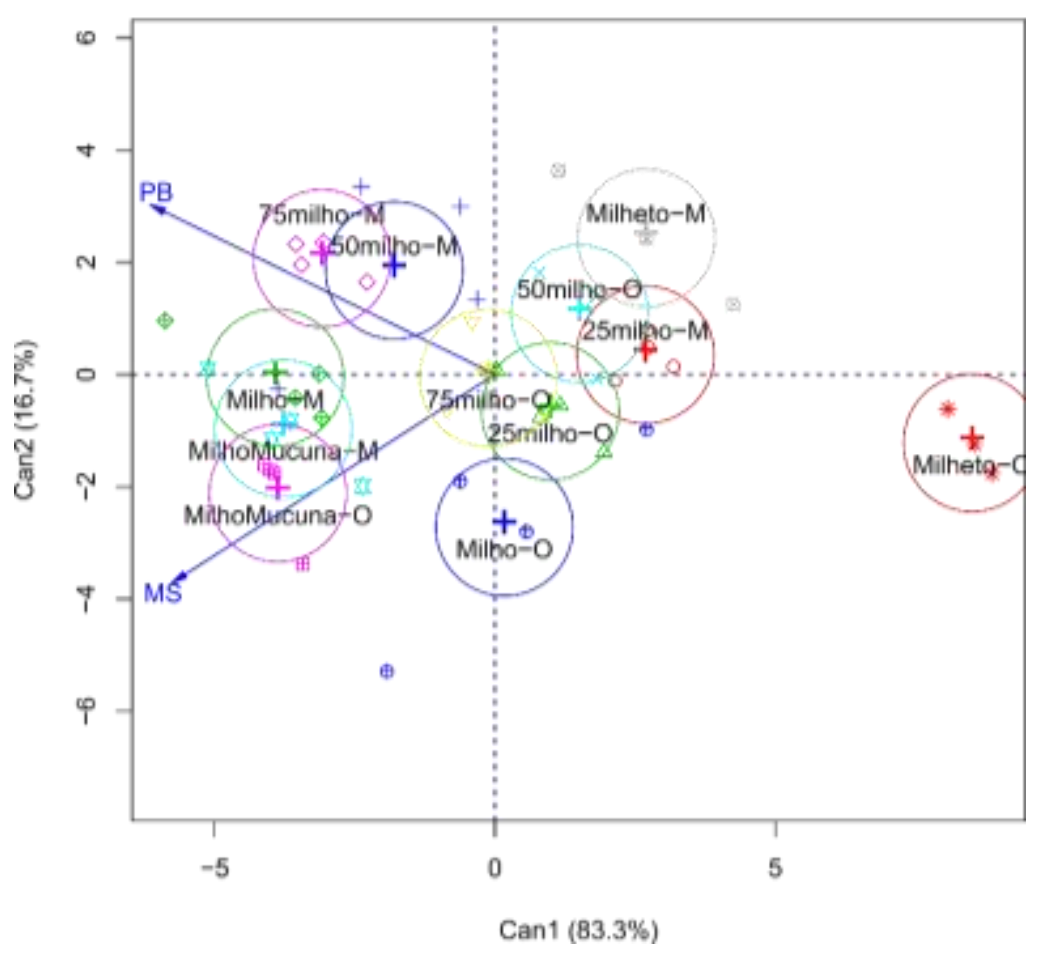

Fonte: Autores.

A utilização da forragem hidropônica é uma alternativa para o produtor de alimentar o gado com garantia de produtividade e proteína utilizando aquilo que é disponível em sua propriedade. Com as análises de variáveis canônicas permite observar que a PB e a MS variam com a população de acordo com o ciclo, como foram conduzidos em épocas diferentes do ano, para cada época uma população pode se desenvolve melhor que a outra.

Precisa-se de mais pesquisas quanto as doses, o tipo de forragem e a época do ano de condução da forragem fertirrigada. Essas informações podem fornecer uma orientação melhor do profissional para o produtor, auxiliando-o na tomada de decisão.

\section{Conclusão}

A população constituída de $25 \%$ milho e $75 \%$ milheto irrigada com solução mineral apresentou melhor qualidade de forragem quanto a proteína bruta. A população de milho e milho + mucuna obtiveram maior matéria seca independente da solução.

Mais trabalhos devem ser desenvolvidos na região para melhores informações sobre o estabelecimento e utilização da forragem hidropônica na região de transição entre o Cerrado e o Pantanal. Para trabalhos futuros também seria interessante realizar pesquisas sobre custos de implantação da forragem hidropônica.

\section{Referências}

Araujo, V. D. S., Coelho, F. C., Da Cunha, R. C. V., \& Lombardi, C. T. (2008). Forragem hidropônica de milho cultivado em bagaço de cana e vinhoto. Revista Brasileira de Milho e Sorgo, 7(03). 
Bhering, L.L. Rbio: A Tool For Biometric And Statistical Analysis Using The R Platform. Crop Breeding and Applied Biotechnology, 17: 187-190p.

Coelho, F. C., \& Silva, I. T. D. (2018). Variedade crioula de milho na produção de forragem hidropônica com uso de biofertilizante. Cadernos de Agroecologia, 13(1).

Fontaneli, R. S., \& dos Santos, H. P. (2012). Forrageiras para integração lavoura-pecuária-floresta na região sul-brasileira. Embrapa Trigo-Livro científico (ALICE).

Fraga, T. M., Ferrari, L., Garcia, A., Leite, D. C., \& Tannous, S. (2009). Influência de três variedades de milho (Zea mays, L.) E dois substratos na produção de forragem hidropônica. Nucleus Animalium, 1(1), 1-12.

Heberle, E., Araujo, E. F., Lacerda Filho, A. F., Cecon, P. R., Araujo, R. F., \& Amaro, H. T. R. (2019). Qualidade fisiológica e atividade enzimática de sementes de milho durante o armazenamento. Revista de Ciências Agrárias, 42(3), 657-665.

Müller, L., Santos, O. S. D., Manfron, P. A., Medeiros, S. L. P., Haut, V., Dourado Neto, D., \& Garcia, D. C. (2006). Forragem hidropônica de milheto: produção e qualidade nutricional em diferentes densidades de semeadura e idades de colheita. Ciência Rural, 36(4), $1094-1099$.

Neumann, M., Ghizzi, L., Junior, J. C. H., Carneiro, M. K., Reinehr, L. L., Spada, C. A., \& Maciel, G. S. (2017). Produção de forragem de milho em diferentes densidades de semeadura e épocas de colheita. Revista Brasileira de Milho e Sorgo, 16(2), 204-216.

Neves, A. L. A. Cultivo de milho hidropônico para alimentação animal. CPT. 242p.

Oliveira, L. B. D., Pires, A. J. V., Carvalho, G. G. P. D., Ribeiro, L. S. O., Almeida, V. V. D., \& Peixoto, C. A. D. M. (2010). Perdas e valor nutritivo de silagens de milho, sorgo-sudão, sorgo forrageiro e girassol. Revista Brasileira de Zootecnia, 39(1), 61-67.

Piccolo, M. A. (2013). Forragem verde hidropônica de milho produzida em substratos orgânicos residuais utilizando água residuária de bovino. Revista Ceres, Viçosa, 60(4), 544-551.

Píccolo, M. A., Coelho, F. C., Gravina, G. D. A., Marciano, C. R., \& Rangel, O. J. P. (2013). Produção de forragem verde hidropônica de milho, utilizando substratos orgânicos e água residuária de bovinos. Revista Ceres, 60(4), 544-551.

de Lima Rodrigues, M., Vasconcelos, L. C., Garcia, R. V., Costa, A. C., de Melo Reis, B., \& de Lima, W. L. (2017). Cultivo de forragem hidropônica agroecológica de milho em diferentes concentrações de biofertilizante. Anais da $30^{\text {a }}$ Semana Acadêmica do Curso de Agronomia do CCAE/UFES-SEAGRO.

Santana, D. C., Arevalo, A. C. M, Silva, P. R., Kraeski, M. J., dos Santos Zanuncio, A., \& Torres, F. E. (2020). Cultivo de forragem hidropônica de inverno no ecótono cerrado pantanal. Research, Society and Development, 9 (6), e74963377-e74963377.

da Silva, M. R. H., Jobim, C. C., Neumann, M., \& Osmari, M. P. (2018). < b > Corn grain processing improves chemical composition and fermentative profile of rehydrated silage. Acta Scientiarum. Animal Sciences, 40, e42564-e42564.

Simonetti, A., Marques, W. M., \& Costa, L. V. C. (2016). Produtividade de Capim-mombaça (Panicum maximum), com diferentes doses de biofertilizante/mombaça grass productivity (Panicum maximum), with different doses of biofertilizer. Revista Brasileira de Engenharia de Biossistemas, $10(1), 107-115$.

Stivari, T. S. S., Monteiro, A. L. G., de Paula, E. F. E., Fernandes, S. R., de Souza, D. F., \& Gilaverte, S. (2011). Leguminosas na alimentação de ovinos: possibilidades de uso e resposta animal. PUBVET, 5, Art-1205.

Team, R. C. (2013). R: A language and environment for statistical computing.

Vilela, H. H., Rezende, A. V. D., Vieira, P. D. F., Andrade, G. A., Evangelista, A. R., \& Almeida, G. B. D. S. (2008). Valor nutritivo de silagens de milho colhido em diversos estádios de maturação. Revista Brasileira de Zootecnia, 37(7), 1192-1199.

Zorzan, M. H. S. (2006). Avaliação da qualidade de forragem hidropônica de centeio, cevada e ervilhaca (Doctoral dissertation, Universidade Federal de Santa Maria). 